\title{
ENTREVISTA COM O PROFESSOR JOSÉ EDUARDO FARIA (Parte II)
}

Bianca Tavolari (Coordenação e Edição)

Bianca Tavolari ${ }^{1}$, Celso Campilongo ${ }^{2}$, Fernando Rister $^{3}$ e Orlando Villas Bôas Filho ${ }^{4}$ (Entrevistadores)

Em dezembro de 2017, o professor José Eduardo Faria nos recebeu na sala de sua casa, em duas manhãs de sábado, para conversar sobre sua trajetória acadêmica e profissional, sobre as referências que moldaram sua formação, bem como sobre a constituição da sociologia jurídica como campo de conhecimento. Também falamos sobre os rumos da sociologia jurídica já institucionalizada como disciplina e sobre tendências da pesquisa e do ensino em direito.

Todos aqueles que tiveram a oportunidade de ser alunos, orientandos ou, de alguma maneira, ouvir o professor Faria

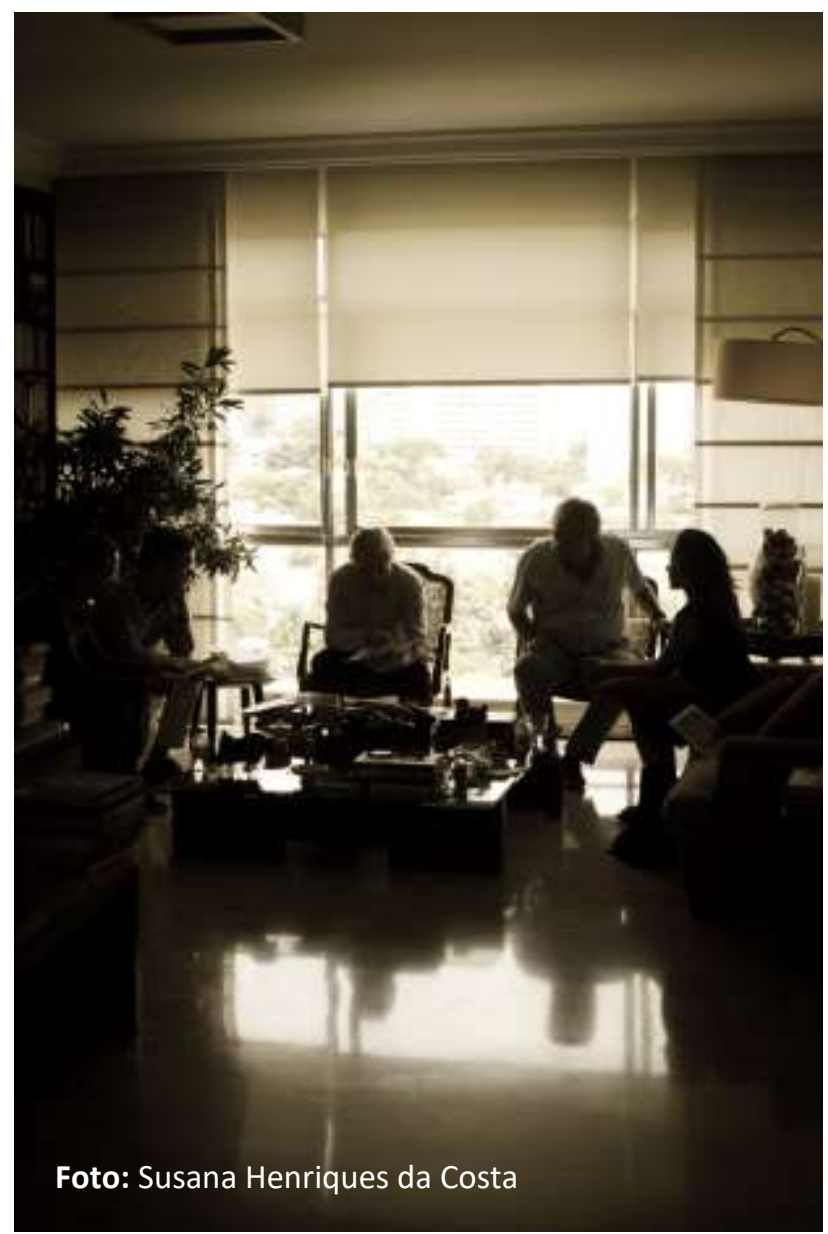
em aulas e palestras sabem que se trata de uma fala arguta, impressionantemente bem concatenada, ágil e repleta de detalhes. Na primeira parte da entrevista, publicada nesta

\footnotetext{
${ }^{1}$ Professora do Insper e pesquisadora do Núcleo Direito e Democracia do CEBRAP.

${ }^{2}$ Professor titular da Faculdade de Direito da Universidade de São Paulo e da Pontifícia Universidade Católica de São Paulo.

${ }^{3}$ Professor da Universidade Presbiteriana Mackenzie.

${ }^{4}$ Professor da Faculdade de Direito da Universidade de São Paulo e da Universidade Presbiteriana Mackenzie.
} 
Revista (v.5, n.2, maio/agosto de 2018), o professor Faria falou livremente sobre sua trajetória. Nesta segunda parte, elaboramos questões específicas que foram previamente enviadas a ele. Em ambas as partes, o leitor encontrará uma narrativa potente, em primeira pessoa, de um dos principais intelectuais da área do direito no Brasil.

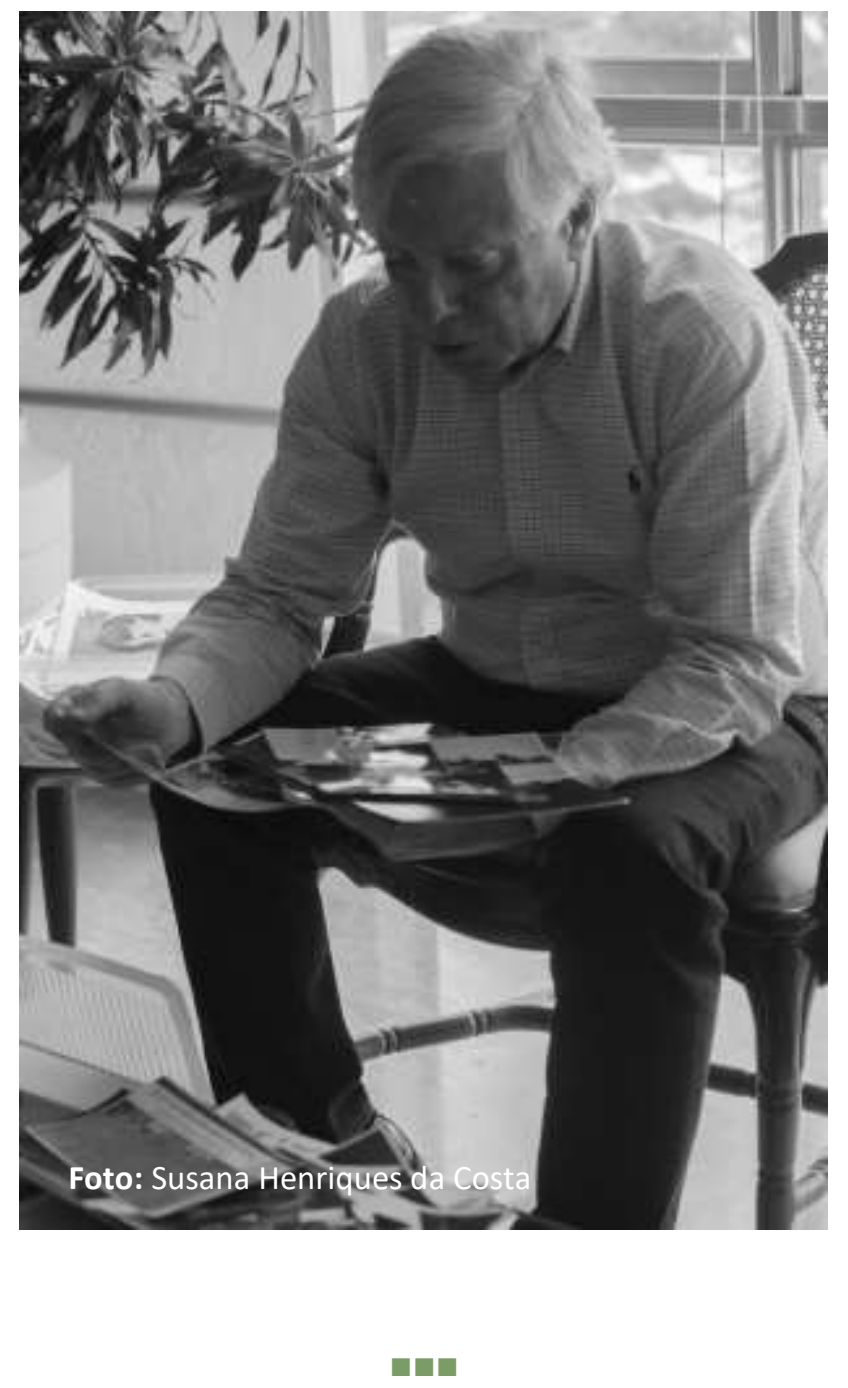

\section{PARTE II}

Entrevistadores: Uma questão pode servir de ponte entre a primeira e a segunda parte de seu depoimento. E ela é bastante simples. Analisando seus livros, ensaios e palestras, vê-se que seu itinerário acadêmico foi muito mais determinado por injunções externas do 
que pela cultura jurídica reinante na Faculdade de Direito. Você concorda com essa observação?

José Eduardo Faria: Sim, de certo modo eu disse algo nesta linha no final do primeiro depoimento. A rigor, pela minha própria origem familiar, meu itinerário intelectual deveria ter sido determinado pelo pensamento jurídico uspiano, já que meu pai foi professor na Faculdade de Direito, meu tio-avô foi catedrático e diretor, além de ter ocupado, por um curto período, a reitoria, e um contraparente ter sido ministro do Supremo Tribunal Federal. Por diferentes fatores, contudo, jamais fui sensível à cultura jurídica uspiana, com seu excesso de formalismo, seus ritos e seus mitos. Pode parecer paradoxal, mas, desde calouro, nada disso me tocou a alma ou me influenciou. Pelo contrário, achava aquilo tudo uma demonstração de irrealismo, de descolamento com a realidade de um país que, entre os anos de 1940 a 1980, havia sofrido uma forte alteração em seu perfil geo-ocupacional. A USP que conheci, de fato, foi aquela criada em 1935 por Júlio de Mesquita Filho, com seu projeto humboldtiano de fazer da Faculdade de Filosofia a alma mater das diferentes áreas de especialização, uma unidade na diversidade, capaz de forjar uma visão de mundo de feições liberais. E o que moldou essa minha visão da USP foram as redações de $O$ Estado de S. Paulo e do Jornal da Tarde. Quando entrei na redação pela primeira vez, em 1968, passei a ver - e até a conviver - com editorialistas que eram docentes formados entre as primeiras gerações de alunos dos professores franceses trazidos pelo Dr. Júlio, como Claude Lévi-Strauss, Pierre Monbeig, Roger Bastide e outros. O liberalismo sempre foi a linha política do jornal e esses franceses, bem como seus alunos que se converteram em docentes, editores e editorialistas, aprofundaram essa linha de caráter liberal clássico com rigor. O ambiente de redação sempre me encantou, como disse na primeira parte da entrevista. Nunca fui advogado ou parecerista. No universo jurídico, tornei-me docente no ano imediatamente após minha formatura e jamais deixei de utilizar, como objeto de discussão em sala de aula, acontecimentos políticos e fatos econômicos que julgava importantes do ponto de vista histórico e que eram debatidos na redação. 


\section{Só você fazia isto naquela época?}

Não. Há algo que não destaquei na parte anterior e diz respeito ao fato de que a carreira acadêmica na área de ciências humanas e sociais deve estar vinculada a uma exposição pública na discussão de grandes temas de interesse da coletividade. Basta ver meus artigos no Estadão e no JT. Eles não eram textos jornalísticos, mas também não eram ensaios acadêmicos. Era algo híbrido, que aprendi com um grupo de professores da USP que trabalharam na empresa, no qual se destacaram, por exemplo, Oliveiros Ferreira, professor de ciência política da USP, Rolf Kuntz, professor de filosofia política da USP, ambos livredocentes, e Sábato Magaldi, que chegou a titular da disciplina de teatro brasileiro na Escola de Comunicações e Artes e sentava-se quase ao meu lado no JT. Mais tarde, surgiria Moacir Amâncio, professor da área de literatura da USP. De certo modo, se puder fazer uma comparação, diria que nosso perfil estava próximo do de Raymond Aron, que era, aliás, reverenciado pela família Mesquita. Tão reverenciado a ponto de ter sido recebido no esteticamente horrendo prédio do bairro do Limão, onde deu uma palestra um tanto quanto burocrática em um evento da empresa que, se não me falha a memória, havia sido promovido pelo Júlio de Mesquita Neto e pelo Ruy Mesquita. Na palestra, ele resumiu dois livros conhecidos e então em voga: Democracia e totalitarismo e Dezoito lições sobre a sociedade industrial. O Aron também tinha dupla carreira, acadêmica e jornalística. Por um lado, foi diretor da École Pratique des Hautes Études e do Collège de France, bem como deu aulas na Alemanha e nos Estados Unidos. Por outro, tinha programa de televisão, era articulista de periódicos importantes e atuava como editorialista, em jornais como Le Figaro e revistas como Commentaire e L'Express. No jornal, quando estávamos de bom humor, levantávamos ao término do almoço e repetíamos um mantra: "vamos trabalhar, vamos enganar o leitor". Um dia, chegamos a nos perguntar se o velho e circunspecto Aron falaria barbaridades como aquela nas redações pelas quais passou. Para concluir a resposta, o fato de eu ter me tornado uma figura visível aos olhos dos meios de 
comunicação aumentou, de certo modo, meu prestígio interno na Faculdade de Direito. Os temas com os quais trabalhei academicamente sempre vieram de fontes externas. Pela redação, circulava muita informação e aquilo era um maná para mim.

\section{Os temas de seu itinerário não surgiriam naturalmente da cultura jurídica interna do} Largo São Francisco, como ocorre com a maioria esmagadora do professorado. São, flagrantemente, temas captados da interação do direito com outras áreas do conhecimento...

Exatamente. Graças a essa minha formação interdisciplinar e ao pouco apego à tradição, aos ritos e aos mitos da Faculdade de Direito, pude identificar e compreender suas contradições, principalmente uma certa simpatia pelo autoritarismo mascarada por uma retórica liberal fundada em lugares comuns. Vejam o que ocorreu em 1964, quando vários docentes apoiaram o golpe e serviram aos militares, inclusive propondo e justificando a censura de imprensa e os expurgos de colegas. E, em 1968 e 1969, apoiaram - e um deles até redigiu - o famigerado Ato Institucional no 5. Havia exceções, é claro. Mas muitos agiram deste modo. Na década seguinte, alguns professores perceberam o gravíssimo equívoco que havia sido cometido. Haviam ajudado na abertura dos portões do inferno para só depois perceberem que tinham perdido o controle da maçaneta. Para tentar limpar a imagem, optaram por uma oposição radical à ditadura militar, sem, contudo, perceberem as nuances que poderiam acelerar uma negociação responsável para a transição rumo à redemocratização do país. Gostaria de fazer uma segunda observação...

\section{Pode continuar.}

Creio que os problemas decorrentes de uma cultura jurídica que não soube se modernizar entre nós, ou seja, que não soube acompanhar a industrialização e a subsequente urbanização da sociedade, resultam da influência francesa, na medida em que as demais áreas da universidade já estavam mais expostas às culturas inglesa ou norte-americana. 
Quando cursei o antigo ginásio, na rede pública, tive três anos de francês e apenas um de inglês. Mesmo na redação isso era visível. O dono do jornal, o Dr. Júlio, foi alfabetizado na Suíça, em colégios internos. Atualmente, devo ser o quinto funcionário com o crachá mais antigo da empresa, um dos poucos com mais de cinquenta anos de casa. O crachá mais antigo, o decano, é justamente de um intelectual francês, Gilles Lapouge, escritor e jornalista que também atuou no Le Monde, no Le Figaro e no Combat. É correspondente do Estadão em Paris e até hoje está muito lúcido, escrevendo com regularidade sobre fatos diversos e sempre e participando de debates na televisão francesa. O ensino jurídico de minha época como aluno era estruturado nos moldes das universidades francesas. No Largo São Francisco, no tempo em que eu era estudante pouco atento ao que diziam nas aulas, os professores com maior poder aquisitivo tinham apartamento em Paris. Eles entravam em sala de aula depois de 9 de março, terminavam o semestre entre 10 a 15 de junho, retornavam em 11 de agosto e acabavam o ano letivo em novembro, ou até mesmo um pouco antes. Nos demais meses, ficavam em Paris. Na USP, o ensino jurídico era controlado basicamente por professores de direito civil de formação normativista, no âmbito do direito, e de viés liberal, no campo da política. Todos ou quase todos temiam e criticavam tudo que cheirasse a luta de classes, ao fortalecimento de sindicatos, à ampliação da participação popular na política e a mudanças no processo decisório nas instituições de ensino superior. Sem rigor conceitual, eram conservadores extremados, inteiramente avessos ao que entendiam como marxismo. Eram defensores do espírito, da forma e dos pressupostos dos Código Civil napoleônico de 1804, tais como autonomia da vontade, propriedade privada e universalidade da lei. Estudei direito exatamente naquele momento de afirmação do processo de industrialização tardia do país, na virada da década de 1960 para a de 1970, que trouxe novos tipos de conflitos, novos valores e novas pautas éticas - mudanças essas não compreendidas por aquela fina flor de juristas liberais formada a partir de leituras de civilistas conservadores franceses, como René Savatier, 
Gaston Morin, Jean Cruet e Georges Ripert, que classificavam a expansão do direito público como "o declínio do direito", "a morte do direito" e a "impotência das leis", uma vez que esta tendência reduzia o alcance do direito privado forjado com base no Código Civil napoleônico. Aqueles meus professores, ou parte expressiva deles, se encaixavam muito bem numa conhecida passagem de Sérgio Buarque de Holanda, em Raízes do Brasil, na qual afirma que somos "desterrados em nossa terra". Nossas instituições e nossa visão de mundo foram importadas de países distantes, com formas de vida distintas. Insisto nesta tecla: graças à influência da tradição jurídica francesa, de natureza ensaística e pouco rigorosa em termos metodológicos, as faculdades de direito, inclusive a do Largo São Francisco, permaneciam alienadas. Com medo do novo, muitos professores aceitaram golpes, cassações e censura, a partir de 1964. Mais grave ainda: com raras exceções, as faculdades de direito ficaram avessas aos contrastes entre o Brasil dos grotões e o Brasil urbano, aos efeitos sociais da concentração de renda e às ideias de planejamento indicativo e coercitivo que estavam presentes no debate político. Seus docentes, em sua maioria, faziam leituras superficiais dos responsáveis pela formação do pensamento social brasileiro, como Oliveira Viana, Alberto Torres, Azevedo Amaral, Sérgio Buarque de Holanda e Gilberto Freyre. Presos a uma tradição francesa que transformava quase tudo numa grande discussão histórica, resistiam a análises empíricas fundadas em pesquisas de campo e dados estatísticos. Eram incapazes de articular os novos saberes advindos de transformações econômicas, sociais e políticas.

A seu ver, quais foram as consequências deste descolamento da realidade, ou seja, das "ideias fora do lugar" defendidas por estes professores de direito, reivindicando o liberalismo político e jurídico em um contexto marcado por profundas desigualdades sociais e regionais, por uma forte concentração de renda, por exclusão e por relações de força paralelas ou acima da ordem legal? 
Todos os fatores somados, mencionados na resposta à pergunta anterior, explicam por que as faculdades de direito, especialmente a da USP, não conseguiram acompanhar as grandes discussões das décadas de 1960 a 1980. Além da questão da redemocratização, estas discussões envolviam temas como planejamento, desenvolvimento, burocracia, corporativismo, nacionalismo e dependência. Durkheim e sua vertente funcionalista pareciam ter sido lidos por meio de vulgatas, enquanto Marx era simplesmente abominado, demonizado. Weber era tão desconhecido por meus professores que um deles, especialista em direito romano e em direito civil, perguntou-me na arguição de meu doutorado quem era esse autor, mostrando desconhecer um pensador e historiador fundamental para compreender a formação do direito no Império Romano, o que dá a medida de sua ignorância. Se com os fundadores da sociologia, os chamados três porquinhos, era assim, é possível imaginar o que esse pessoal dizia a respeito de Foucault e de seus trabalhos sobre formas de poder e disciplina na sociedade contemporânea, de Bourdieu e suas ideias sobre campo jurídico e violência simbólica, e dos frankfurtianos sensíveis à questão do direito e dos direitos, como Habermas, por exemplo. Com uma ou outra exceção, assistentes mais jovens que conheciam algo de Weber haviam lido apenas um pequeno livro escrito por Julien Freund, um pensador franco-germano que havia sido orientado por Raymond Aron. Isso provavelmente acontecia porque a versão em português havia sido publicada por uma grande editora jurídica à época, a Forense. Muitos anos depois, eu iria entrevistar Freund para o Jornal da Tarde. Foi uma publicação em página inteira. Mais tarde, aproveitei esta entrevista para escrever um ensaio introdutório para a tradução do livro sobre Weber de Anthony Kronman, professor de direito comercial, teoria social e sociologia jurídica em Yale. Foi a minha geração docente que introduziu, nas aulas de introdução ao direito e de teoria do Estado, por exemplo, a leitura de $A$ política como vocação. E isso ocorreu quando, na área de ciência política e de ciências sociais da USP, livros como A ética protestante e o espírito do capitalismo e Ensaios de sociologia já 
eram discutidos há bastante tempo. No Largo São Francisco, para estimular os alunos a lerem Weber, também usávamos uma conhecida coletânea organizada por Hans Gerth e Wright Mills.

\section{A tradução teve revisão técnica de Fernando Henrique Cardoso e Octavio Ianni...}

Exatamente. Foi o Programa de Educação Tutorial - PET, já mencionado, que propiciou maior conhecimento sobre Weber na Faculdade de Direito. Na primeira bolsa que ganhei para ir aos Estados Unidos, em 1979, trouxe dezenas de livros sobre ele, alguns hoje considerados clássicos, de autoria de Wolfgang Mommsen, Thomas Burger, S. Eisenstadt e Otto Stammer, por exemplo. Emprestei muitos desses livros a alunos de pós-graduação que os utilizaram em suas dissertações de mestrado e teses de doutorado. Após meu retorno, passei a dar um curso na pós-graduação da UnB, ao lado de Roberto Lyra Filho e Vicente Barreto, e cheguei até a discutir com o diplomata Carlos Henrique Cardim, então professor de ciência política e presidente da editora da universidade, o lançamento de uma coleção weberiana. O projeto chegou a ser elaborado, mas não houve recursos suficientes e ele acabou engavetado, o que foi uma pena. Posteriormente, a UnB publicou Economia e sociedade, numa edição primorosa. Em São Paulo, originariamente os bolsistas do PET liam esse livro na tradução espanhola publicada pelo Fondo de Cultura Económica. Eram dois volumes que eu havia trazido de uma viagem ao México, também em 1979. Eles tinham uma característica peculiar. O livro estava esgotado há tempos. Fuçando nas livrarias Gandhi, Porrúa e Herder, na cidade do México, acabei encontrando o tomo número um e o tomo número dois. Mas o primeiro volume era de uma edição e o segundo era de outra. Foram os únicos exemplares que achei. Com a leitura do Weber pelos bolsistas do PET, os alunos das disciplinas de teoria do Estado e introdução ao direito foram progressivamente tomando consciência de que a política, os partidos políticos, as empresas e o próprio Estado estão sujeitos a crescente burocratização, ou seja, ao predomínio das regras racionais, da hierarquia e da impessoalidade nas relações de 
dominação, o que é inerente ao desenvolvimento das relações capitalistas modernas. Isso já vinha sendo discutido em larga escala na Faculdade de Filosofia e nos cursos de administração de empresas e administração pública da FGV, mas a temática era inédita no Largo São Francisco.

\section{Em termos temáticos, qual é o denominador comum de sua trajetória acadêmica?}

Esta questão me veio à cabeça em diferentes ocasiões. Num primeiro momento, achei que não sabia respondê-la. Mais tarde, David Trubek, por um lado, e Boaventura Santos, por outro, chamaram-me atenção para o fato de que eu discutia o direito em movimento. Ou seja, o direito como processo de controle técnico-político em sociedades instáveis ou em mudança, como é o caso da brasileira. Fazendo uma retrospectiva dos meus trabalhos, tenho a impressão de que o denominador comum é a relação entre mudança social, mudança econômica, mudança política e mudança jurídica. Ou seja, trabalhei com o engate e o desengate entre a estrutura jurídica e a estrutura socioeconômica, entre a estrutura política e a eficácia jurídica, entre transição política e efetividade das instituições políticas. Trabalhei, também, com a tensão entre economia, por um lado, e política e direito, por outro. Essa tensão é resultante do confronto entre a busca da eficiência alocativa pelos economistas e empresários e a busca pela legitimação no poder pelos políticos. A busca da eficiência econômica tende a corroer a ordem política estabelecida e as bases de sustentação dos governantes, enquanto a busca e a manutenção do poder pelos políticos tendem a comprometer a racionalidade econômica. Ainda nessa linha, trabalhei, igualmente, com a dificuldade de se legislar e manter estável uma ordem jurídica em sociedades cambiantes que não conseguem ter rotina, comportamentos sedimentados e expectativas comuns de justiça. Trubek foi decisivo para afinar meu olhar sobre esse tema. E o que talvez tenha reforçado minha opção por estudar estas questões foi minha 
experiência como jornalista - olha aí, estamos voltando para a primeira pergunta desta segunda parte.

No começo da minha carreira no Jornal da Tarde, ia muito a Recife, para fazer matérias sobre a Sudene, e a Fortaleza, onde fica a sede do Banco do Nordeste do Brasil, o BnB. Na época, os dois órgãos contavam com uma burocracia jovem, tecnicamente bem preparada e consciente de que os desequilíbrios sociais e regionais só poderiam ser corrigidos mediante ação do poder público, por meio de planejamento, reformas estruturais, fontes compensatórias de emprego e medidas fiscais voltadas à correção do que os integrantes da equipe de Celso Furtado chamavam de "formas abusivas de consumo". De tanto fazer planos para ficar os sábados e domingos em Recife, fui conhecendo a competente burocracia do órgão e vários outros estados nordestinos. A ideia de mudança foi ficando cada vez mais clara na minha cabeça e acabou sendo chave para entender a tensão entre vigência e eficácia em sociedades desiguais e heterogêneas, como a brasileira e a moçambicana - esta última para onde iria, décadas depois, participar de um projeto financiado pela ONU e coordenado pelo Centro de Estudos Sociais, da Universidade de Coimbra. No caso do Brasil, em 1940, em números aproximados, 68\% da população brasileira viviam no campo e $32 \%$ nos centros urbanos. Quatro décadas depois, os números haviam se invertido: $68 \%$ da população viviam nos centros urbanos, com forte presença no Sudeste, e $22 \%$ no campo. Essa mudança tão intensa obrigou o governo federal a enfrentar o desafio de promover alfabetização e qualificação profissional, criar condições para assegurar inclusão social, oferecer saúde, transporte, segurança e moradia. Evidentemente, isso acarretou enormes dificuldades para as diferentes instâncias do poder público, que não dispunha de recursos orçamentários para arcar com investimentos em infraestrutura e programas sociais. Foi por causa dessas mudanças e desses desafios subsequentes que comecei a examinar com mais cuidado a questão do impacto fiscal do processo de industrialização tardia do país. Das conversas com os técnicos da Sudene e do BnB aos livros sugeridos por Rolf, entre outros, e com leituras dos papers produzidos pelo 
pessoal do luperj e do Cebrap, fui me concentrando cada vez mais na tensão entre direito, vigência e eficácia, nos instrumentos jurídicos necessários para formular e implementar o desenvolvimento, na incapacidade do direito para acomodar as estruturas sociais em períodos de transformações intensas e perversas. De tanto ir ao nordeste, por um lado, e a Brasília, por outro, a questão do desenvolvimento, a noção de estratégia, as funções do Estado e a questão dos direitos tornaram-se prioritárias. Elas estão presentes na minha tese de doutorado, intitulada Direito, modernização e autoritarismo: mudança socioeconômica $x$ liberalismo jurídico. Também estão presentes na tese de titularidade, publicada pela Editora da USP, Eficácia jurídica e violência simbólica. E estão presentes, ainda, em Direito e economia na democratização brasileira, um dos trabalhos que me deu mais prazer em conceber e escrever. A primeira tese, a de doutorado, jamais foi publicada. Havia fechado um acordo com uma editora importante, por intermédio do Florestan Fernandes Jr., mas não tive o tempo necessário para revê-la e a oportunidade foi perdida. A versão apresentada à banca examinadora foi impressa numa máquina que fazia talão de cheques, no banco em que então trabalhava. Por isso, a tiragem acabou sendo mínima. Hoje só tenho dois exemplares dela.

\section{Desenvolvimento foi um tema importante da década de 1960 e você o retomou na} década seguinte, não?

Sim, foi um tema importante nos anos 1960, bastante discutido no Rio de Janeiro pelo pessoal do ISEB, por meio de Hélio Jaguaribe, Álvaro Vieira Pinto, Guerreiro Ramos e Carlos Estevam Martins, que anos mais tarde se tornaria meu amigo. Para estes intelectuais, o pensamento social e político brasileiro havia se tornado ultrapassado como instrumento de interpretação do Brasil que emergia com o avanço da industrialização, exigindo, assim, a elaboração de uma ideologia e um projeto nacional-desenvolvimentista. Também era bastante discutido em São Paulo por Fernando Henrique Cardoso, especialmente em 
Política e desenvolvimento em sociedades dependentes e Dependência e desenvolvimento na América Latina, escrito em parceria com Enzo Faletto.

Como estudante de direito na virada da década de 1960 para a de 1970, lembro de que eu vagabundeava na faculdade, cabulando as medíocres aulas de direito romano e teoria do Estado. Às vezes ia assistir algumas aulas como ouvinte na Faculdade de Filosofia, na Maria Antonia. Outras vezes fazia o circuito das livrarias, no centro, e sempre passava na Mestre Jou, que ficava na rua Martins Fontes, quase ao lado do prédio do Estadão. Ouvi uma vez, num debate na Filosofia, alguém falando em Karl Mannheim. Um dia, voltando da Maria Antonia para o jornal, o vendedor da Mestre Jou, que me tinha sido apresentado pelo Rolf, me chamou e anunciou a chegada de uma nova remessa de Liberdade, poder $e$ planejamento democrático. O livro abriu meus horizontes. Lembro de que li e reli o livro nas então morosas viagens a Recife, nos lentos Electra 2 da Varig. 0 avião fazia escalas no Rio e em Salvador, o que levava a viagem a durar umas monótonas cinco horas. Essas leituras foram decisivas para a entrevista que faria, algum tempo depois, com Gunnar Myrdal, o vencedor do Nobel de Economia de 1974, dividido com Friedrich Hayek. O livro de Mannheim também me ajudou a entender o polêmico 2o Plano Nacional de Desenvolvimento (PND), lançado no final daquele ano, e a escrever uma sucessão de matérias e artigos sobre ele. Artigos e matérias que, por sua vez, foram fundidos e expandidos num livro em que, doze ou quatorze anos depois, analisei a Constituição promulgada em 1988 sob o olhar da sociologia do direito. Trata-se de O Brasil pósConstituinte, editado por Fernando e por Marcos Gasparian no selo Graal, da Editora Paz e Terra.

\section{E como foi que você passou da questão do desenvolvimento para temas como} movimentos sociais, acesso aos tribunais e democratização da Justiça?

Acho que foi uma passagem natural, uma vez que o fracasso do $2^{\circ}$ PND deixou uma mão de obra ociosa nas periferias marginalizadas das regiões metropolitanas, exponenciou a 
questão das desigualdades e agravou o problema do hobbesianismo social. Essa mão de obra ociosa carecia de qualificação e havia migrado para o sudeste para atuar no término das grandes obras do regime militar. Como não havia dinheiro para novas obras, a partir dos anos finais da década de 1980, ela foi expulsa da economia formal. Isso trouxe novos atores à cena política, como é o caso não só dos movimentos sociais, mas, igualmente, de uma magistratura jovem na primeira instância e preocupada em aplicar o direito a partir de uma hermenêutica mais sensível aos princípios jurídicos do que às regras e de uma advocacia mais engajada, que foi objeto de uma das mais importantes pesquisas do Centro de Estudos Direito e Sociedade. Esta pesquisa resultou, entre outras coisas, num instigante ensaio de inspiração weberiana preparado pelo Celso Campilongo, distinguindo dois tipos ideias de advocacia - a tradicional e a inovadora. Os movimentos sociais reivindicaram novos direitos, por um lado, e a aplicação dos direitos já existentes, por outro. A luta pela democratização no acesso aos tribunais levou a mudanças processuais importantes, permitindo o ingresso de conflitos coletivos em um judiciário originariamente organizado para julgar conflitos inter-individuais. Os advogados inovadores organizaram grupos que souberam explorar a sistemática de prazos e recursos da legislação processual, para pressionar juízes e criar situações de fato para governantes, como foi o caso dos pesquisadores e advogados militantes do Instituto Apoio Jurídico Popular, criado pelo Miguel Pressburger, no Rio de Janeiro, e do grupo do Gabinete de Assessoria Jurídica Popular (Gajop), criado no âmbito da Comissão de Justiça e Paz em Olinda e Recife, na época de D. Helder Câmara. O objetivo do Ajup e do Gajop era formar advogados comprometidos com as lutas populares, prestando assessoria jurídica aos segmentos mais desfavorecidos da população. Apesar de suas diferenças e de suas especificidades, os dois institutos publicaram dezenas de cartilhas ensinando e treinando líderes populares a usar o direito vigente para favorecê-los. Tem uma passagem ilustrativa dessa estratégia na Cartilha no 2 do Gajop, publicada em junho de 1985. Diz ela: “O desprezo pela via jurídica 
como solução para certos problemas implica o desperdício de uma oportunidade para a conquista de ganhos reais. Existem determinadas leis que favorecem, sob diversos aspectos, as lutas populares e resultam não apenas da vontade das classes dominantes, mas do somatório de vários fatores que concorrem para a produção do direito". O uso inteligente da legislação processual, com o objetivo de deter ou acelerar certos despachos judiciais, era um desses fatores. Já a magistratura se dividiu numa ala mais socialdemocrata, que formou o movimento Juízes para a Democracia, ou numa linha mais à esquerda, como o movimento do Direito Alternativo. No meio de tudo isso, dada a sucessão de convites para falar para advogados militantes e juízes ativistas, mapeei as dificuldades das instituições judiciais para decidir conflitos em torno de valores excludentes e o preço que tinham de pagar por suas sentenças, podendo comprometer sua autoridade e sua credibilidade. Conceder ação de reintegração de posse contra movimentos sociais e ser acusado de estar ao lado dos proprietários? Ou negar a reintegração e ser acusado de politizar a interpretação jurídica, tomando, no limite, decisões contra legem em favor dos movimentos? Aplicar com rigor a legislação de proteção ambiental e ser acusado de prejudicar o crescimento econômico? Ou ter uma posição mais branda e ser acusado pelos ambientalistas de ter sido cooptado pela iniciativa privada?

Reaparece aí a pergunta já anteriormente feita, sobre o denominador comum dessas suas pesquisas, não?

É verdade. O fio condutor das pesquisas foram as tensões entre legalidade e legitimidade, entre governabilidade e legitimidade e entre vigência e eficácia do direito. Tensões essas que acabaram sendo objeto de meus cursos de pós-graduação sobre pluralismo jurídico, exclusão, movimentos sociais e ativismo judicial, democratização no acesso à justiça, reformulação da legislação processual e reforma do judiciário. Essas tensões e esses temas também foram objeto de ensaios e palestras no decorrer das duas últimas décadas. Estão 
presentes em três livros que produzi nesse período. O primeiro foi Justiça e conflito: os juízes em face dos movimentos sociais, publicado em 1991. O segundo foi Direito e justiça: a função social do judiciário, uma coletânea que organizei com base em ensaios importantes de sociólogos do direito, como o Campilongo, o Boaventura, o Zé Reinaldo e outros. O terceiro livro foi $A$ crise do direito numa sociedade em mudança, também uma coletânea com textos de meus colegas do Departamento de Filosofia e Teoria do Direito, que saiu pela Editora da UnB. Desses livros, só um, o primeiro, saiu por uma editora especializada em temas jurídicos. Os outros dois saíram por editoras especializadas em sociologia, o que é revelador, a meu ver, do tipo de atuação interdisciplinar que caracteriza minha carreira. Esses três livros, um dos quais teve várias tiragens, levaram-me a ser sistematicamente convidado para dar palestras em grupos heterogêneos, de comissões de justiça e paz a sindicatos, de movimentos sociais a associações de magistrados, de centros acadêmicos a entidades empresariais, da CNBB à Federação do Comércio de São Paulo, o que me fez rodar e voar por um país de dimensões continentais, atuando ao lado de colegas como Celso Campilongo, José Reinaldo de Limas Lopes e José Geraldo de Souza Júnior, entre outros. Saía às quintas à noite e voltava aos domingos, também à noite, o que me permitiu conhecer a realidade social das cinco regiões e me propiciou vários insights para desenvolver meus cursos de pós-graduação e definir os temas das teses de meus orientandos. Trazia pilhas de informações e dados estatísticos, que convertia em tabelas. Apresentava tudo num retroprojetor, coisa que faço até hoje. Estes dados dão fundamento empírico ao que digo na graduação e na pós-graduação.

De tanto viajar para palestras e de integrar comitês de área de agências de fomento à pesquisa, como o CNPq, acabei me envolvendo cada vez mais com a questão da reforma do ensino jurídico numa perspectiva crítica, o que me levou a ser vice-presidente da Associação Latinoamericana de Metodologia do Ensino do Direito (Almed), então chefiada por uma figura a um só tempo intelectualmente brilhante, politicamente contestadora e 
socialmente sedutora - e, na somatória de todas essas características, um personagem tão influente quanto polêmico. Trata-se do argentino Luís Albert Warat, que tinha uns dez anos mais do que eu e com quem tive ampla e insólita relação acadêmica e pessoal. Além de ter me chamado para esta entidade, indicou-me para o conselho editorial de uma revista que tinha granjeado prestígio entre as novas gerações de estudantes latinoamericanos de direito e ciências sociais. Com um nome quilométrico, Contradogmáticas: revista intercontinental para uma teoria crítica do direito, ela foi criada para catalisar as críticas ao positivismo jurídico e desnudar o que seus colaboradores chamavam de mito do saber racional inerente à ideia kelseniana de uma teoria pura do direito, que empresta ao universo das ideias uma ordem hierárquica necessária, capaz de conferir ao conhecimento científico o caráter de caminho único da verdade. A ideia era mostrar que o positivismo jurídico, à época profundamente impregnado nos cursos de direito, não passava de uma técnica de controle social, destinada a nos ensinar a agir conforme a natureza das coisas. Ora publicada em espanhol, ora em português, a revista tinha como proposta catalisar um pensamento crítico integrado por um conjunto de contra-linguagens que, sem constituir um corpo sistemático de categorias, formasse um conglomerado de significações, de esboços políticos e teóricos que permitisse questionar as concepções juridicistas sobre lei e coerção, por meios das quais as formas jurídicas e estatais são apresentadas como instrumento de caráter técnico e as relações jurídicas são entendidas com um sentido específico, que afasta a compreensão de sua fundamentação nas relações sociais. Warat propunha uma inversão da razão jurídica então prevalecente nas faculdades de direito, que estabelecia uma análise juridicista e não política do Estado, valorizando, justamente, o oposto, ou seja, um discurso que pretendia falar politicamente do Estado e, por tabela, do direito. Sou devedor de Warat por suas orientações, críticas e lições de direito e de vida que me deu. Fomos companheiros de algumas experiências engraçadas, se vistas aos olhos de hoje. Numa delas, participamos de uma banca de livre-docência numa respeitada universidade federal. De meia-idade, cabelo louro solidamente armado com laquê, sóbrio 
tailleur de cor suave e salto alto, a candidata era filha de um conhecido general. Foi a tempestade perfeita. Deu tudo errado. No primeiro dia do concurso, um antigo reitor dessa universidade, ex-membro do Conselho Federal de Cultura e então acometido de esclerose, apareceu no Salão Nobre, sentou na principal cadeira, afirmou que presidiria os trabalhos e disse que a candidata merecia as notas máximas da banca. Foi constrangedor vê-lo sendo afastado do recinto por antigos catedráticos, tão idosos como ele. Como a tese era muito fraca, as arguições de Warat e minha foram duras. No último dia do concurso, enquanto ouvíamos a prova didática e esperávamos o momento de lançar as notas, vimos a instalação, na sala ao lado, de um enorme bufê e a chegada de um sem-número de pessoas vestidas a rigor, para comemorar a conquista do título. O que não aconteceu, pois, como as notas de Warat e as minhas foram muitíssimo baixas, a candidata não alcançou a média e foi reprovada. Quando o presidente da banca anunciou o resultado, para perplexidade de todos, o general avermelhou-se, encheu o peito e ameaçou iniciar um discurso feroz e violento, o que levou uma prudente e hábil assistente da diretoria a pedir nos dirigíssemos às pressas, Warat e eu, para a garagem e a solicitar que fossemos o mais rapidamente para o aeroporto, numa kombi caindo aos pedaços. O veículo não foi escolhido para nos humilhar, mas por estratégia. Mais precisamente, para que passássemos desapercebidos e não fôssemos surpreendidos no caminho por um capitão ou major subordinado ao exasperado pai da fracassada candidata. Outra experiência foi um sorvete que Warat e eu tomamos certa vez com Niklas Luhmann, numa tarde de verão sob um calor mais forte do que a canícula andaluza. Enquanto o primeiro era extrovertido, transgressor e tendia a aumentar a voz e a se mexer na cadeira quando estava animado, 0 segundo era tímido, discreto, contido, falava baixo e, pior, monocordicamente. Claro, Luhmann defendeu a teoria dos sistemas, como era de se esperar. Explicar como se inspirou no conceito de "autorreprodução da espécie", da biologia, para introduzir, no direito, o conceito de autopoiese. Além de discutir sistemas autorreferenciais, falou sobre 
complexidade paralisante, dupla contingência, fatalidade do acaso e conhecimento como "qualidade não-hierárquica". Warat, sem esconder o desprezo por aquelas ideias, repetiu o mantra contradogmático e enfatizou a tese foucaultiana de que o grande jogo da história será de quem se apoderar das regras, de quem tomar o lugar daqueles que as utilizam, de quem se disfarçar para pervertê-las, utilizando em sentido inverso contra aqueles que as impuseram. Quando dei por mim, o sorvete de ambos havia virado uma untuosa sopa que pingava na gravata, na camisa e no paletó de ambos e eles já não sabiam bem do que estavam falando. Mas eram enfáticos em seus discursos e narrativas. Foi uma cena engraçadíssima, absolutamente surreal, e que parecia ter sido extraída de um dos programas do grupo Monty Python.

$\mathrm{Na}$ primeira parte da entrevista, ficou clara a importância, para sua formação intelectual, dos seminários com o professor Rolf Kuntz. Quais eram as atividades desenvolvidas e em que medidas elas são importantes para a formação do sociólogo do direito nos dias de hoje?

É preciso lembrar que foram dois seminários, ambos absolutamente informais. Um deles era somente entre o Rolf, recém iniciante na carreira acadêmica, formado na USP na Fundação Getúlio Vargas, e eu. Às vezes, participava o Reinaldo Lobo, que, com o tempo, trocou o jornalismo e a filosofia pela psicologia. O outro era coordenado pelo Frederico Heller, um engraçadíssimo e competente economista alemão, autor de uma tese de doutorado sobre a economia e a social-democracia, que emigrou para o Brasil por causa do nazismo. Além de chefe da seção econômica do Estadão, participou de bancas de doutorado de na USP e em outras universidades e foi um dos criadores da Associação Nacional de Pós-Graduação em Economia (ANPEC). No caso específico do Rolf, as primeiras leituras foram de Locke e Hobbes, no âmbito da filosofia; de autores como David Apter, David Easton, Karl Deutsch, Reinhard Bendix e Gabriel Almond, por exemplo, no campo da ciência política; de Weber e Mannheim, no caso da sociologia. E Herbert Hart, no campo 
do direito. Também orientou leituras de macroeconomia e economia política, tendo me apresentado aos escritos de Keynes e Schumpeter. Foi a partir da leitura de Socialismo, capitalismo e democracia, por exemplo, que tomei consciência do que era o processo de criação destruidora, característica das transformações desenvolvidas por empreendedores de diferentes portes. Foi ali que comecei a perceber melhor as dificuldades de regulação desse processo, à medida que impõe aos juristas o ônus de reformular categorias tradicionais na definição do objeto jurídico. Rolf foi quem me apresentou o João Paulo Monteiro, lembram-se? Foi, também, quem, como meu chefe do JT, determinou que eu descesse para Santos uma vez por semana, para cobrir a Bolsa de Café e o porto. Igualmente, foi ele quem sugeriu que eu frequentasse as reuniões plenárias e os departamentos técnicos da Fiesp, que funcionava na frente do prédio onde hoje está o Ministério Público, a menos de cem metros da Faculdade de Direito. Conheci ali, por exemplo, o José Mindlin, o Dilson Funaro e o Laerte Setúbal, que não se misturavam com a velha geração de empresários beneficiados pela ditadura, como Theobaldo de Nigris, conhecido por cortejar os militares. Ali também me aproximei de técnicos de alto refinamento intelectual, alguns dos quais lecionavam na FGV. A Fiesp também trazia com regularidade, para palestras, dirigentes governamentais, políticos e intelectuais. A Fiesp tinha, ainda, um banco eficiente e respeitado de dados. Foi ali que comecei a compreender melhor as discussões sobre projetos de poder para o Brasil, sobre a definição de prioridades e sobre fixação de metas. Quando comecei lecionar no Largo São Francisco, fazendo os seminários de Introdução ao Estudo do Direito, descobri que podia usar aquelas discussões como contraponto fático para as questões de teoria do direito. Gostei tanto que, com o tempo, também passei a frequentar a Federação do Comércio como repórter, tendo sido mais tarde convidado para integrar o Conselho de Economia e Sociologia, que contava com gente respeitada e qualificada como Dorival Teixeira Vieira, da Faculdade de Economia da USP, Claudio Contador, da UFRJ, Julian Chacel, da FGV, 
ambos assíduos, e Roberto Campos, esse muito absenteísta. Com isso, as explicações ficavam mais claras, os alunos gostavam e os debates se aprofundavam. Vez ou outra, trazia algum técnico da Fiesp ou algum jovem professor da FGV para os seminários, o que foi considerado um pouco excêntrico para uma escola de direito. No início, os seminários eram aos sábados de manhã e tinham alto comparecimento. Além do rico material propiciado para minhas aulas na USP, essas experiências foram decisivas para minha carreira no jornalismo. Elas me ajudaram a ter uma compreensão sistêmica das cadeias produtivas. Isso me levou a ganhar um Prêmio Esso de Informação Econômica, em 1974, por causa de uma série de reportagens que mostravam a trajetória de um pé de alface, da terra à sua venda num supermercado. O outro seminário acontecia aos sábados num canto da redação do antigo prédio do Estadão, na Rua Major Quedinho, quando o velho Heller reunia o Rolf, o Robert Appy, o Eduardo Jardim, o Arnaldo de Alencar Lima e eu para debater. Também convidava ministro e secretários da área econômica e líderes empresariais e dirigentes de organismos internacionais para conversas francas, abertas, mas em absoluto off. O engraçado é que éramos observados de modo irônico e por vezes provocativo pelo principal editorialista político do jornal, Miguel Urbano Rodrigues. Português exilado por causa da ditadura salazarista, com uma formação marxista ortodoxa, militante histórico do Partido Comunista Português e irmão do escritor Urbano Tavares Rodrigues, era quem escrevia os editorais mais conservadores da empresa. A ideia do Heller sempre foi discutir problemas mais estruturais do que conjunturais do país. Eu devia ter uns 21 anos, estava na metade da faculdade quando ingressei no grupo e o aprendizado foi decisivo tanto para minha carreira acadêmica quanto para o trabalho que, mais tarde, faria no Itaú, assessorando o Olavo Setúbal. Se o primeiro seminário foi decisivo para minha formação intelectual, o segundo foi decisivo pela abertura inédita de horizontes, levando-me a entender que a busca pelo rigor científico não se restringe ao plano teórico, estendendo-se igualmente ao plano metodológico. 
Como você e seus colegas de área, como o Joaquim Falcão e o Luciano de Oliveira, encararam a sociologia antes que o programa da disciplina de sociologia jurídica estivesse definido?

No meu caso, parti de dois ângulos. O primeiro envolvia a distinção entre uma sociologia europeia, de natureza ensaística e mais sensível a grandes interpretações históricas, e uma sociologia americana, mais preocupada com o rigor nos recortes temáticos, análises empíricas, coleta de dados e informações estatísticas. Falando em termos muito amplos, os sociólogos com formação europeia argumentavam, na época, que seus colegas com formação americana tendiam a perder tempo com coleta de dados pouco significantes, que faziam generalizações desprovidas de fundamentos sólidos e que se deixavam levar por consensos prévios de natureza mais ideológica do que científica. Já os sociólogos com formação americana afirmavam que seus colegas europeus falhavam ao tentar fazer grandes interpretações unitárias da sociedade, uma vez que elas se baseavam em generalizações indevidas e não no conhecimento rigoroso dos fatos. O segundo ângulo envolvia a discussão então travada sobre um certo esvaziamento da própria sociologia como atividade intelectual. A ideia era de que a sociologia teria esgotado sua contribuição para a compreensão da organização e funcionamento da sociedade, encontrando-se num momento de desorientação ante as novas questões trazidas pelas novas formas da vida social, por um lado. E também teria perdido parte de seu campo ou jurisdição com o avanço da ciência política, da antropologia, da economia e até mesmo da filosofia, por outro lado. No caso da antropologia, por exemplo, dizia-se então que ela teria avançado sobre a sociologia quando passou a estudar o impacto da ascensão dos movimentos sociais sobre as práticas tradicionais da política, depois de se converter numa disciplina preocupada com o conhecimento dos segmentos da população que foram levados à marginalidade política, econômica e social pelas sucessivas etapas do processo de industrialização. No caso da filosofia, a discussão era no sentido de que ela vinha 
propiciando reflexões mais profundas do que a sociologia. E, no caso da economia, era indiscutível o sucesso das correntes clássicas e da corrente marxista na análise dos sistemas de organização social e política posteriores à revolução industrial. Evidentemente, esta distinção teve impacto nas primeiras etapas da sociologia do direito, marcadas por uma oposição entre estudos sociológicos de processos e sistemas jurídicos com base em investigações empíricas, por um lado, e análises fundadas na tradicional pesquisa teórica e bibliográfica, mais próximas da ciência do direito, por outro lado. Não sei qual seria a seria posição do Joaquim com relação a essas distinções, mas creio que o Luciano certamente concordará comigo. Foi a partir desse cenário que definimos os programas de sociologia do direito, opondo a pluralidade de espaços socioeconômicos à noção do espaço político unificado comum à teoria do Estado, contrapondo o pluralismo jurídico à ideia de monismo jurídico comum à teoria do direito, sobrepondo as novas formas de ação política na luta por novos direitos à ideia de representação partidária comum ao direito constitucional. Não foi por acaso, como disse na primeira parte desta entrevista, que a sociologia do direito acabou sendo mal recebida nos cursos de direito, quando se converteu em disciplina obrigatória.

Essa foi a "etapa heroica" da disciplina, como você e o Campilongo escreveram no último capítulo de a Sociologia Jurídica no Brasil, em 1991.

É verdade. Isso explica, como o Celso e eu afirmamos nesse livro, quando ainda não tínhamos cabelos brancos, que a unidade da sociologia do direito entre as décadas de 1970 e 1980 foi assegurada por alguns inimigos comuns. Dentro das faculdades de direito, onde lecionavam pessoas como Warat, Joaquim, Gisele Cittadino, Eliane Junqueira, Luciano de Oliveira, Campilongo, Zé Reinaldo e eu mesmo, esse inimigo eram os professores de formação formalista e positivista. Independentemente de serem publicistas ou privatistas, a tentativa de nos desclassificar como docentes numa faculdade de direito era permanente e feroz. A ponto de, em um de meus concursos na USP, ter sido 
classificado expressamente como subversivo durante a arguição do professor Caio Tácito. De certo modo, isto voltaria a ocorrer em outro concurso, quando o professor o ministro José Carlos Moreira Alves, mais refinado do que Tácito, afirmou, de modo educado, mas enfático, que os sociólogos do direito não têm o mesmo conhecimento dos magistrados para estudar as instituições judiciais. Se, no plano interno dos cursos jurídicos, os inimigos comuns eram a dogmática, o legalismo e o formalismo, no plano externo, o inimigo era a crítica à ditadura e ao autoritarismo.

\section{Então a unificação e a própria organização do campo da sociologia do direito foram}

\section{dadas por elementos externos a ela?}

É verdade, vocês têm razão. Foram as próprias condições políticas e sociais nas quais emergiu a sociologia do direito no Brasil que fizeram com que ela se defrontasse com adversidades, resistências e antagonismos para se afirmar como uma disciplina acadêmica específica entre as várias áreas jurídicas. No início, a unidade da sociologia do direito não foi propiciada por definições de metodologia, por autores de referência e por modelos de pesquisa. Foi dada, isto sim, por razões de sobrevivência, resultantes das posições de poder de determinados catedráticos e titulares de universidades públicas que, por controlarem o campo jurídico, arvoravam-se na prerrogativa de dizer o que é e o que não é direito, quais são os limites epistemológicos do conhecimento jurídico, como deve ser tratada a questão do valor na ciência do direito e o que deve e o que não pode ser objeto das pesquisas jurídicas. Em face das chamadas guerras palacianas, esta luta pela sobrevivência foi fortemente viabilizada, entre outros fatores, pelo apoio externo de André-Jean Arnaud, diretor científico do International Institute for Sociology of Law, em Oñati, de Boaventura Santos, presidente do Centro de Estudos Sociais, em Coimbra, de David Trubek, do International Studies Institute da Wisconsin University, em Madison, de Juan-Ramón Capella, chefe do departamento de filosofia do direito da Facultat de Dret de 
Barcelona e de Raffaele di Giorgi, da Università del Salento, em Lecce. Todos ajudaram com convites para passarmos períodos fora. Assim, tínhamos acesso a bibliotecas atualizadas e começamos um processo de integração em redes internacionais de pesquisa. Começamos a ter um prestígio externo que soubemos converter em influência interna e garantir espaços, como o Grupo de Trabalho Direito e Sociedade, da ANPOCS, que cheguei a dirigir por dois anos. Mas, note que, nesse período, não apenas demos os primeiros passos para definir as fronteiras do nosso campo, enfatizando a importância de uma concepção pluralista de direito e de suas fontes de produção, como também estabelecemos alguns fios condutores para nossas análises, tais como a tensão entre a perspectiva interna e a perspectiva externa do direito, ou seja, a tensão entre uma sociologia do direito dos juristas e a uma sociologia dos sociólogos; a crítica à autodefinição do sociólogo do direito como observador acrítico objetivo, que somente descreve os fatos; o dogma da separação radical entre o âmbito do ser e do dever ser, com a subsequente crítica dos juristas aos sociólogos, por limitarem o olhar apenas à facticidade; e a negação à sociologia do direito da possibilidade de formalizar seu objeto de conhecimento, o que poderia levá-la a se converter em mera ciência auxiliar da ciência do direito. Evidentemente, corremos riscos sérios nessa etapa - e por culpa nossa. Enfatizávamos a importância da interdisciplinariedade, por exemplo. Mas talvez tenhamos demorado um pouco para tomar consciência de que o acesso à abertura interdisciplinar poderia desfigurar a sociologia do direito como disciplina epistemologicamente autônoma. Também começamos a falar muito em pesquisa sem, contudo, ter formação estatística e sem ter em mente que o excesso de foco na coleta de dados tende a desprezar o fato de que os chamados "fatos do direito" não se apresentam de forma bruta na realidade socioeconômica. São, como vários de nós escreveríamos depois, fatos construídos mediante um processo de interações entre o objeto do conhecimento e o sujeito cognoscente, em que o caráter jurídico da facticidade do direito não pode ser visto apenas em termos de ação e organização social. Entre as heranças que o Cediso deixou, uma delas 
foi a consciência de discutir o que seria pesquisa, a diferença entre pesquisa qualitativa e pesquisa e o rigor metodológico com conhecimento de estatística. E, principalmente neste último ponto, Ana Lúcia Pastore Schritzmeyer, hoje professora do Departamento de Antropologia da USP, teve um papel a um só tempo decisivo e impecável. Como também foi o papel de Maria Cecília MacDowell, minha antiga orientanda de mestrado que me foi encaminhada por Joaquim, hoje professora da Universidade da Califórnia, em São Francisco, e autora de uma bela pesquisa sobre a tragédia ocorrida na Vila do Socó, em Cubatão, em fevereiro de 1984, causada pelo vazamento de um oleoduto da Refinaria Presidente Bernardes. Até hoje recomendo aos meus orientandos que, antes de começar a redigir suas teses, primeiro leiam o trabalho da Cecília.

A sociologia do direito é um campo amadurecido de pesquisa? Se houve amadurecimento, ele veio acompanhado de especialização? Como você vê o quadro atual da pesquisa empírica na área de direito no Brasil?

Creio que foi com o início da Assembleia Constituinte, em 1987, e nos anos seguintes ao da promulgação. Até então, a unidade da sociologia jurídica estava na negação ao autoritarismo e à dogmática, como já disse. Demorou algum tempo para que dedicássemos maior atenção para as dimensões epistemológicas, históricas, teóricas e sistemáticas da sociologia do direito. Isso só aconteceu após a queda do regime militar e do retorno ao regime democrático, quando as coisas mudaram. Combatíamos o formalismo, o dogmatismo, o positivismo e o legalismo, mas o que poderíamos e deveríamos fazer em matéria de reconstrução institucional quando éramos convidados pelos constituintes a colaborar? Tínhamos formação suficiente para passar da simples crítica acadêmica ao desafio de erguimento de uma nova ordem legal, em função dos convites que nos foram feitos à época? Joaquim Falcão, por exemplo, integrou a Comissão Arinos, encarregada pelo governo Sarney de preparar uma minuta de Constituição. Haviam 
cogitado meu nome para integrar essa comissão, por sugestão do Olavo Setúbal, ministro das Relações Exteriores desse governo, mas fatores diversos me levaram a ser deslocado e integrar a Comissão de Reforma da Universidade, criada no âmbito do Ministério da Educação. Nunca conversei com o Joaquim sobre como ele atuou e enfrentou as dificuldades surgidas na sua comissão. Mas do meu lado, no momento em que me vi à frente das discussões sobre a reformulação da universidade pública num país complexo, heterogêneo e desigual, percebi com clareza que o amadurecimento do campo da sociologia do direito teria de ser inexoravelmente acompanhado da especialização. Aquele foi um período em que recebi convites para falar não só de questões educacionais, mas, igualmente de questões políticas e constitucionais em comissões técnicas da Constituinte, nos institutos de vários partidos políticos, em associações empresariais, em sindicatos trabalhistas, em entidades de operadores jurídicos e em centros vinculados à Igreja. E, quanto mais falava, mais tomava consciência da necessidade de rever minha formação técnico-jurídica. Ou seja, rever minha formação dogmática para poder pensar e implementar novas formatações jurídicas. Encerrados os trabalhos da Constituinte e com a sedimentação da nova Constituição nos anos seguintes, mediante uma progressiva pacificação de entendimentos judiciais com relação à nova ordem jurídica, a sociologia do direito profissionalizou-se de vez - e, basicamente, a partir de análises quantitativas cuidadosas, na linha da tradição da sociologia americana. Não sei se a palavra profissionalização é a mais correta. Mas é a que melhor designa um processo de diferenciação funcional de temas e o advento de locais de trabalho não acadêmicos propiciados pela criação das áreas de pesquisa do Conselho Nacional do Ministério Público e do Conselho Nacional de Justiça, pela criação da diretoria de Estado, Instituições e Democracia, pelos levantamentos financiados pelo Banco Mundial e pelo BID e encomendados pelo Ministério da Justiça para orientar a reforma do Poder Judiciário, por estudos pedidos por ONGs, entidades como a Ford Foundation, associações empresariais, think tanks, instituições filantrópicas constituídas por grandes empresários. Vejam, nesse 
sentido, a área de pesquisa jurídica aplicada da FGV, em São Paulo, onde se destacam a Luciana Gross, e os centros de pesquisa em direito e economia, de justiça e sociedade e de tecnologia e sociedade da FGV, no Rio de Janeiro. Vejam, também, o brilhante trabalho feito pelo grupo do Luís Werneck Vianna sobre o perfil socioeconômico da magistratura brasileira, o trabalho do Marcos Nobre no Núcleo Direito e Democracia no Cebrap de o trabalho feita pela Maria Teresa Sadek, a Teca, quer no grupo constituído pelo Kazuo Watanabe, quer em sua passagem pelo CNJ. Não se pode esquecer, ainda, das pesquisas do Núcleo de Estudos da Violência, da USP, do Centro de Estudos sobre Cultura Contemporânea (Cedec) e do grupo Poder Judiciário, Conflito e Sociedade da FGV-Rio, bem como de vários outros centros vinculados a universidades federais.

Com a expansão da disciplina, é possível dizer que houve uma incorporação da sociologia do direito - ou de uma perspectiva sociológica pautada no conflito e na pesquisa empírica - pelas disciplinas dogmáticas? A institucionalização da disciplina levou a uma diluição do campo nas matérias dogmáticas que eram antes combatidas, como direito penal, administrativo, econômico, entre outras?

Não creio. Houve, é certo, uma tendência das novas gerações de professores de direito penal, direito administrativo e direito econômico de se aproximar da sociologia do direito. A meu ver, esse era um processo inevitável. Lembrem-se da experiência do PET, na Faculdade de Direito. Financiado pela Capes, ele foi criado há 40 anos na área específica da sociologia do direito. Mas, uma vez consolidada a formação dos bolsistas nessa disciplina nos dois primeiros anos, eles são obrigados a buscar uma área de especialização nos dois anos seguintes. E isso levou a algo que não foi suficientemente estudado: o aparecimento do chamado PET Crime, constituído por bolsistas preocupados em estudar a violência e segurança, e o PET Econômico, integrado por bolsistas preocupados em estudar moeda e regulação. O PET Crime foi responsável pela formação de duas das mais brilhantes 
professoras de direito penal do país, Maíra Rocha Machado e Marta Rodrigues Machado. Elas lecionam direito penal e sociologia do direito na FGV, em São Paulo, participam das atividades do Instituto Brasileiro de Ciências Criminais (IBCCrim), entidade criada por magistrados, promotores e criminalistas, e têm sido convidadas a dar consultoria às comissões técnicas do Senado e da Câmara que apreciam os projetos de reforma do Código Penal e do Código de Processo Penal. No caso do PET Econômico, já perdi a conta dos egressos que, com formação e especialização em sociologia do direito, ocuparam cargos no CADE, na CVM e no Ipea. Em outras palavras, as áreas de direito penal, direito administrativo e direito econômico passaram por transformações paradigmáticas e precisaram abrir mão da exclusividade da dogmática por estratégias de caráter interdisciplinar. Isso, contudo, não levou à diluição do campo da sociologia do direito nessas áreas.

Para encerrar, em $\mathrm{O}$ Estado e o direito depois da crise, você traçou algumas hipóteses e cenários a respeito da transformação do direito depois da crise financeira de 2008. Já estamos em quase dez anos de pós-crise. Como você avalia as transformações que aconteceram no direito nesse meio tempo?

Essas transformações, como já dizia no livro, aceleraram o processo disruptivo das novas tecnologias de comunicação. Multiplicaram as redes internacionais de atividades, de conhecimento e de poder. Agravaram ainda mais a erosão dos poderes hierarquizados, a corrosão da ideia de soberania absoluta e o desempoderamento dos Estados nacionais. Levaram a política a se deslocar rapidamente para a conexão comunicativa entre diferentes atores e organizações internacionais e supranacionais. Ampliaram a exclusão social, o retrocesso no campo dos direitos humanos e o esvaecimento das identidades e das culturas nacionais. E geraram situações paradoxais, o que pode ser visto pelo desdobramento do aumento do conhecimento científico e do saber técnico, pelo aumento do medo, pelo aumento da insegurança, pelo aumento das contingências sociais e pelo 
aumento de retrocessos civilizatórios, decorrentes das vitórias de populistas e da extrema direita na Europa e na América Latina. Ao longo destes anos, as teorias tradicionais do direito perderam o que ainda lhes restava da capacidade de responder a várias questões fundamentais. Tenho trabalhado sobre algumas delas. Como justificar a violência em casos de necessidade? Como definir a agressão injusta? Como avaliar as consequências das transformações causadas pela crise financeira de 2008 sem modelos cognitivos que nos ajudem a compreendê-las com maior precisão? Como lidar com as mudanças nas relações entre o espaço em períodos de erosão política e de emergência de diferentes temporalidades? Enfim, se os esquemas cognitivos das concepções tradicionais de direito foram concebidos para tempos de normalidade, ou seja, de relativa estabilidade, como lidar com as mudanças intensas e radicais nestes tempos de incerteza e instabilidade? Enquanto a falta de imaginação e a aversão ao diálogo interdisciplinar prevalecerem no âmbito de um ensino jurídico incapaz de buscar respostas para essas questões, por um lado, e de trazer para a sala de aula a discussão sobre um resgate ético da esperança frente à voracidade do sistema financeiro internacional, por outro, não há como se deixar de lado o ceticismo da razão - o pessimismo como método. Como os historiadores, os sociólogos do direito muitas vezes são portadores de verdades inconvenientes. E, no seu trabalho diário, não se cansam de se mostrar capazes de enxergar o mundo como de fato é, sem flertar com o descolamento da realidade, como ocorre com as abordagens reinantes nos cursos jurídicos do país, onde o formalismo, o dogmatismo e o positivismo descritivista, que, por tenderem a ver o direito basicamente como um sistema fechado, expandem-se em função da dinâmica interna de seus conceitos e métodos, independentemente do mundo real, das lutas e dos poderes sociais, econômicos, políticos e culturais. 